\title{
Novas Cartas para as Damas: \\ Leitura de A Dama e o Unicórnio, de Maria Teresa Horta e de Vozes, de Ana Luísa Amaral
}

\author{
Maria Lúcia Dal Farra \\ CNPq-São Paulo
}

Resumo: A partir da leitura de A Dama e o Unicórnio, de Maria Teresa Horta, e de Vozes, da Ana Luísa Amaral, a proposta é conhecer como, passando pelas Novas Cartas Portuguesas e pela interlocução contemporânea com o feminino, ambas as autoras escrevem, de novo, suas cartas para esse mesmo espelho no qual se transfiguram ou se refletem. Depois disso, fica para o leitor a decisão de discernir quem está preso (na cadeia ou nas letras da tradição cultural e literária) - se a Dama, se o Cavaleiro.

Palavras-chave: tradição literária, feminino, Literatura Comparada, Novas Cartas Portuguesas, Maria Teresa Horta, Ana Luísa Amaral

\begin{abstract}
By doing a comparative reading of A Dama e o Unicórnio [The Lady and the Unicorn], by Maria Teresa Horta, and Vozes [Voices], by Ana Luísa Amaral, and looking at New Portuguese Letters and the contemporary dialogue with the feminine, the proposal is to address how both authors, Horta and Amaral, write their letters to the same mirror in which they are transfigured or reflected. After this, the reader is left with the decision to determine who is incarcerated (in jail or in the letters of the cultural and literary tradition) - whether the Lady or the Knight.
\end{abstract}

Keywords: literary tradition, feminine, Comparative Literature, New Portuguese Letters, Maria Teresa Horta, Ana Luísa Amaral 
Nos Dispersos de Cecília Meireles, publicados pela primeira vez em 1997, no Rio de Janeiro, lê-se um longo e tocante poema que começa apontando abruptamente que, na prisão, se encontram quatro mulheres. E, à medida que o poema avança, o número de mulheres enclausuradas vai-se multiplicando freneticamente: de quatro para quarenta, de quarenta para quatrocentas, de quatrocentas para quatro mil e, destas, para quatro milhões - dando-nos conta de que, afinal, no caso do feminino, o encarceramento não é um estado de exceção. Leio a última estrofe:

Quatro mil mulheres, no cárcere, e quatro milhões - e já nem sei a conta, em cidades que não se dizem, em lugares que ninguém sabe, estão presas, estão para sempre - sem janela e sem esperança, umas voltadas para o presente, outras para o passado, e as outras para o futuro, e o resto - o resto, sem futuro, passado ou presente, presas em prisão giratória, presas em delírio, na sombra, presas por outros e por si mesmas, tão presas que ninguém as solta, e nem o rubro galo do sol nem a andorinha azul da lua podem levar qualquer recado à prisão por onde as mulheres se convertem em sal e muro. (Meireles 1997: 1759-60)

Trago para aqui este poema (que tem indicialmente o título de "Prisão") como uma 
espécie de umbral de entrada (e espero que de saída) desta questão sobre as Damas, de que quero me ocupar agora. Porque, tal como estas mulheres de Cecília (egressas de todos os tempos) e tal como a Mariana Alcoforado (madre seis-septcentista), também as visadas Damas (medievais) de Maria Teresa Horta e de Ana Luísa Amaral se encontram em cárcere privado. Delas, só Mariana parece estar (digamos) “legitimamente” retida, visto que é freira, e que o convento tornou-se, embora contra a sua vontade, o seu lar. No entanto, sabemos, é pelo seu corpo, cuja voz as Três Marias enunciam e traduzem pouco a pouco nessa incisiva escrita de alforria feminina que são as Novas Cartas Portuguesas (1972), que esta Sóror se evadirá do claustro, estorcendo-se em prazeres nunca dantes ousados, multiplicando-se em mulheres de ventre e orgasmo sem peias.

Exemplário de liberação feminina, tal obra é certamente referência e espelho, mensagem e novas cartas para as Damas que habitam os derradeiros livros de Horta e de Amaral, vindos a lume no ano passado. Acrescentando-lhes mais e mais imagens e perspectivas, elas atualizam agora essa "epistolografia” (em que todas nós, mulheres, nos inscrevemos e nos escrevemos), revisitando a nossa história, vasculhando-a então a partir da Idade Média, para transmitir um novo grito de guerra às gerações vindouras. Não é, pois, uma simples coincidência que uma das Três Marias seja a autora de uma das duas produções que trago agora, e que Ana Luísa Amaral, a mais insigne dos comentadores dessa fundante obra de 1972, seja a outra.

Assim como as Cartas da Freira Portuguesa foram, para as três mencionadas escritoras, a "sombra ligeira", a "sílaba" que ficou decantada no fundo do "cesto" esvaziado, para que elas o pudessem preencher com mais e mais "sílabas" e mais "outras palavras" também as Novas Cartas parecem ter-se tornado resíduo comum aos "cestos" de Maria Teresa Horta e de Ana Luísa Amaral, já então enquanto "rastilhos" e "bombas", propiciando-lhes os respectivos "momentos de ladrão". Pois não é exatamente essa a operação literária de escrita?!

"Pá, limpa o cesto!" - eis a palavra de ordem de Ana Luísa Amaral, implícita em seu poema "Palimpsesto", incluído nesse seu mais recente livro, Vozes (Amaral 2013: 41). E é nessa obra, entre trovas e sextinas, que a sua Dama se encontra presidiária. Ela se acha 
atada às malhas da escrita, lugar, afinal, bem acolchoado, verdadeiro ninho de "algodão em rama". O problema é que as folhas de papel pertencem ao Cavaleiro, são sua propriedade e por ele manipuladas (idem: 50). E o Cavaleiro, malgrado seja seu senhor, quer tirar de lá de dentro a nossa Dama; e ela, que tem razões e argumentos próprios, não vai fazer-lhe a vontade: insiste, na contramão do desejo dele, em ali permanecer.

Bem, essa é a cena dialogada que os quatro longos poemas de "Trovas de memória" descerram ao nosso entendimento, providenciando, entre os dois contendores, um bate-boca muito significativo, e ao qual tentarei dar voz.

Já em Maria Teresa Horta, a Dama que, durante todo o percurso dos poemas, se vê livre para ir de um para outro canto, acaba por restar perpetuamente amarrada, embaraçada e presa pela linha, pela lã, pelos laços, pela tinta, pela trama ardilosa das tapeçarias, onde, afinal, ela vai exibir para a eternidade a "infindável e incomensurável cadeia" que a agrilhoa ao Unicórnio (Horta 2013: 139).

Em Horta, o vocábulo de base, que aciona a passagem da Dama para diferentes destinos, para um e outro dos diversos estratos em que ela se desloca com desenvoltura, é a "fresta": a fenda entreaberta, o intervalo, o sulco, a fissura da tela em processo de bordadura, que providencia a comunicação entre os vários componentes da tapeçaria.

Se, de um lado, essa brecha metaforiza o corpo feminino e seu sexo, sua entrada e abertura para o mundo, pois que é o “aceso vulcão/da boca do seu corpo" (idem: 40), por outro, e paradoxalmente, encerra o destino histórico e fatal da mulher, seu fechamento e cárcere. Não nos esqueçamos que o Unicórnio, seu comparsa nessa trama, ${ }^{1}$ e cujo corne tem “o poder do delito" (idem: 113), também se associa, num de seus mitos, à virgindade corrente que a tem algemado por eras e eras. Assim, a propensão da mulher à abertura, ao movimento, ao trânsito, acaba por convocá-la à prisão que a Dama da tapeçaria tem ostentado durante séculos para a humanidade: a da imobilidade perene, a do amordaçamento, a de alguém que, embora emita uma "fala", não encontra para esta o "mundo" que a ouça e que lhe dê sentido - axioma que, afinal, encarna um signo só significante, sem significado ainda, muito semelhante à concepção do "não-toda" lacaniano. E descrevo o livro de Horta a fim de que possam me acompanhar nessa especulação. 
Composto por 72 peças, a obra divide-se em seis grandes quadros, à imitação do número dessas mencionadas tapeçarias medievais: "Arte e ofício", "As personagens", "As tapeçarias”, “0 mito”, “À mon seul désir" e "A eternidade”. Tais conjuntos de poemas ficam resguardados por outros: pelo que os antecipa e pelo que os finaliza, de maneira a que estes componham um cadre, uma moldura que vai tanto conter os grupos que perfazem o fulcro da obra, quanto evitar que a Dama se solte e se escapula para todo o sempre. Cada conjunto se apresenta intervalado por outro grupo de poemas sempre intitulado "Ad limina", e que fazem as vezes de divisórias, de biombos, de anteparos entre uma parte e outra. Sua função é semelhante à da didascália: tais grupos realizam um escrito poético paralelo, com índole crítica, informativa ou explicativa acerca dos blocos adjacentes.

Além disso, agrega-se aos poemas um aparato das artes visuais, da música e do canto: as fotos das célebres tapeçarias de Cluny, recortadas com vistas a cada poema; a “cantata profana" de Antonio de Sousa Dias; e a "recitação" do livro por Ana Brandão ambos acoplados ao volume como cd anexo. Tais apetrechos e mais a estrutura que os poemas desenham vão conferir ao livro de poemas de Horta o aspecto de um espetáculo e, mais que isso, um espectro lírico-teatral de auto-medieval (digamos) pós-moderno. Vejamos.

Na sua grande maioria, os versos dos inúmeros poemas se apresentam em medida dita "pequena": em quadrissílabos, em hexassílabos, em redondilhas menores e maiores e, excepcionalmente, em octassílabos, para culminarem numa mistura entre decassílabos e alexandrinos na massa de encerramento, que, por isso mesmo, parece ostentar uma feição classicizante. Aliás, a preocupação latente no título deste derradeiro quadro, "A eternidade", vem acentuar tal perfil com a persistente interrogação da Dama, no início de cada um dos seis últimos poemas, que vem à boca de cena para nos indagar em desespero: - "O que faço da minha eternidade?"

De resto, tem-se a impressão que a medida dos versos revisita as eras, os tempos literários, começando pela faixa temporal da confecção das tapeçarias na Idade Média (segunda metade do século XV), até trazê-las para a nossa contemporaneidade, que se estampa na desmesura das sílabas poética e nos versos brancos. Ora, todos esses recursos 
confluem para flexionar uma caleidoscópica leitura lírica da condição feminina através de diferentes retomadas de cada uma das seis tapeçarias medievais francesas conhecidas como "La Dame à la Licorne": "A vista", "O ouvido", "O gosto", "O olfato", "O tato", "À mon seul désir". E a tal ponto, que aquilo que pertence a um dos tantos patamares de existência da tapeçaria fica sempre disponível e prestes a entrar em contato com outro e outro patamar, muitas vezes praticando uma interessantíssima intersecção de camadas, prodígio da tal mencionada "fresta" que, assim, se revela um eficaz expediente técnico-semântico propiciador dos trânsitos do feminino.

Eis como os objetos do plano material (oficina, tear, lãs, linha, agulha, tinta, bobinas, artesãs, artista, pontos de bordado, desenhista, talagarça, tela, etc.), daquilo que diz respeito ao "entrançamento" da tapeçaria, do seu universo infra-estrutural, passam a se cruzar e a conviver com os materiais do nível da "urdidura" da tela. Ou seja: com os seres, os objetos, os animais e as vegetações do enredo, bem como com todos os estratos sócio-culturais e míticos que foram se apensando aos quadros ao longo dos séculos - trâmite que alcança até mesmo a escrita dos poemas.

É quando a poesia se torna, então, trabalho manual de desenredamento, de desconstrução, de desocultação e de reorganização dos materiais anteriores, e, para o caso - tanto dos componentes das tapeçarias quanto daqueles do poema. De maneira que a obra de Horta vai, assim, localizando agudas visões sobre a condição da mulher, interrogando sobre o comportamento dos gêneros, ao mesmo tempo que, metalinguisticamente, se põe buscando dar conta daquilo que vai produzindo pouco a pouco. Já se vê que é nessa agitação interna que a Dama ganha vida própria.

É assim que os nós dos pontos tropeçam nos dedos das artesãs diante do olhar da Dama e das meadas de lã; é assim que as dobras dos vestidos da Dama escondem interditos; que as bordadeiras tocam o corpo da Dama e esta se entrega ao afago; que os sons do verso assimilam o ruído do bosque onde habita o Unicórnio; que as tecedeiras ondulam diante do Unicórnio como a seduzi-lo; que o fole da harpa tangida pela Aia ajuda na voz da frase; que as fiandeiras tentam capturar com suas linhas, no afã de materializá-lo, ao Unicórnio; que a destreza do artesão toca o modelo, que vibra; que o ritmo do vento no bosque ingressa no 
zunido do verso; que Geneviève de Nanterre e Claude Le Viste, mãe e filha, confundidas pelo artista numa só mulher, tornar-se-ão muitas - o próprio Eterno Feminino: Helena de Tróia, Dalila, Medusa, Penélope, Artemísia, Alice, Eurídice; e que o Unicórnio se transmuta em Pégaso, em cisne, anjo, noviço, cordeiro, narciso, Estrela Polar e em todos os símbolos da água, espelhando a operação de transfiguração - alegoria do próprio trabalho poético. Afinal, a poesia de Horta, desmanchando o referencial existente, dissolvendo-o, acaba por rearranjá-lo de um outro modo, realizando o prodígio do "solve et coagula” da Opera Magna que, simbolicamente, o conjunto das tapeçarias ensina: "visita interiora terrae, rectificando invenies occultum lapidem" (cf. Evola 1975).

Muito embora todo esse mundo esteja prenhe de vida e dinamismo por baixo, por dentro e à superfície da tapeçaria, nada, na sua rasura, parece fulgir ou mexer. Porque é dali, daquele limiar, que a Dama, como mulher, nos olha impassível, naquela referida "fala sem mundo" - muito embora traga no peito o coração amotinado. Ela se acha perdida na mesma floresta de utopias que o Unicórnio, e nos exibe a mesma eterna história sem saída, personagem de uma fábula que a inventa:

As tapeçarias fecham-na. As tapeçarias

acorrentam-na, as tapeçarias encarceram-na

(Horta 2013: 140)

Já em Ana Luísa Amaral, é o Cavaleiro quem quer desenjaular a Dama, que se encontra presa na sua letra, na sua tinta, entre rimas impuras - enfim, confinada nos seus cadernos. ${ }^{2}$ Atada à escrita, à cola e ao papel, ostentando "esculturas de arame" sobre o corpo - o espartilho? a espiral da brochura? -, a Dama parece desconfiar do convite, visto que resiste e que, até o fim do arranca-rabo, não vai ceder.

Ela, pelos vistos, deve ter sido muito importante: causou conspirações e espantos, até disputas na arena. Talvez por isso mesmo, o nosso Cavaleiro nada possa contra ela, porque, durante os quatro longos poemas, dois em redondilha menor, dois em hexassílabos, as intenções, promessas e argumentos desse senhor não serão em nada suficientes para demovê-la de seus propósitos de ali permanecer embutida. E, para o caso, é bem isso: os 
arrazoados dele são inoperantes para tirá-la do seu lugar, muito embora ele tenha se esforçado demais para retê-la ou - sabe-se lá? - para espantá-la dali, visto que até já a atravessara com a caneta... Índice erótico?! O Cavaleiro é decisivamente muito dúbio.

Para induzi-la a saltar do caderno e a vir ter com ele, ele vai contar, dentre os seus recursos, com o de utilizar métrica diversa e, mais ousadamente, com um outro método mais original: o da língua inglesa e francesa. E olhem que a língua, neste caso, não é apenas a falada ou escrita, mas também aquela matizada de "fogo" e "mel de lume" (Amaral 2013: 50)! A intenção do Cavaleiro, como sublinhei, não é nem um pouco unívoca!

E seu discurso se mostra ser, também, muito persuasivo. É mesmo mutante, bem ao sabor das conveniências: deslizante, camaleônico, despistante. De um lado, ele arroga não querer vê-la morrer ali embutida nas folhas, ao que ela retruca, desdizendo-o, não estar lá dentro o inferno, mas sim fora do texto. De outro, ele reclama contra o lança-chamas que ela direciona para ele (porquanto ele preferisse a luz da lua), e se queixa do efeito ótico (hipnótico?) que ela (certamente ao torná-lo seu leitor) exerce sobre ele.

Mas a Dama pretende mesmo é despedi-lo, livrar-se dele: quer deixar de ser seu apêndice e deseja ser esquecida por ele. Que ele arranje outro caderno, outra senhora e um frasco de sais - aliás, dois destes quatro poemas têm por título este enigmático "sal de memórias". Quanto a si, a Dama escolhe permanecer perdida entre as folhas do caderno, tão macias quanto já foram um dia as mãos dele, das quais, aliás, ela abdica de vez: não quer nenhuma proteção que lhe ofereça, insiste! E se ele não aceita a sua decisão, que a expurgue, que a queime junto com o caderno, como na Inquisição, e que espalhe suas cinzas pelos mares do sul...

Bem. Como na língua nativa e em redondilhas, a coisa não avança, o Cavaleiro passa então para as sextinas, em inglês e em francês. E, já agora, não lhe pede mais a mão, mas afirma que se contenta apenas com um dedo! Jura que não passará dos limites e que nem sonha em encontrá-la de corpo inteiro páginas à frente! Que seu amor é apenas platônico, blábláblá, e assim por diante: que até aceita dela um mísero sorriso, contanto que seja em folha. Mas logo se contradiz: seu instinto de posse torna a aflorar, e o novo argumento é que, embora sejam dela as linhas, afinal o caderno é dele - autoridade é autoridade! 0 fato é 
que, seja em inglês ou em francês, o Cavaleiro pretende mesmo é levá-la para outro continente, pra lá onde há “quase uma cordilheira/de nada e de silêncio" (Amaral 2013: 51) - quer amordaçá-la com o seu suposto amor?

$\mathrm{Na}$ folha de que é cativa, tentada e tocada pelo acento francês e pela palavra em inglês, a Dama se acha, por momentos, indecisa, desalentada. Mas não demora a se resolver: regressa logo à língua (que é sua), à redondilha (medida que é sua) e à acolchoada e santa folhinha. Mas o digno Cavaleiro parece não desistir e ainda tenta tirá-la mais uma vez para fora do caderno, e, desta feita, puxando-a (deselegantemente) pelo nariz!

Para além da irreverência, finura da discussão e das deliciosas insinuações, enfim, para além do "sal" picante, não há dúvida que tais poemas procuram revisitar, através do tempo, códigos literários ancestrais: aliás, em todas as quatro nomeações, a palavra "memória" está sempre nos advertindo disso. E, neste caso específico, Ana Luísa Amaral quer mesmo é pôr em crivo, empenhada e implicitamente, um dado estético da Idade Média: o estatuto cortesão da Cantiga d'Amor medieval e, através dele, a condição feminina incrustada e confinada há séculos nesse gênero.

Dando direito de voz à mulher engaiolada em tal convenção, ela nos leva a ouvirmos as suas expressões de vontade, escarafunchando também o seu desejo que, nestes poemas, é posto em prova. De maneira que, por este viés, a convenção amorosa vai definitivamente para as cucuias: a pretensa "cantiga d'amor" se transforma numa quase altissonante "cantiga de tenção", aquela que comporta uma disputa em pé de igualdade. A Dama não é, em Ana Luísa Amaral, o fantoche, o modelo feminino obediente, reverente e passivo, a quem o Trovador presta homenagem feudal simulando ser vassalo - e não seria também esta a convenção entre Unicórnio e Dama? Aqui, ao contrário das senhas amorosas e da mesura, ele não consegue disfarçar o seu poder sobre ela, já que pretende, por toda a lei, passar por cima dos ditames da Dama, pois que não se capacita a convencê-la de suas razões.

Dama e Cavaleiro se apresentam um diante do outro, desvestidas as máscaras convencionais (embora se forjem outras de mera estratégia de relação): tanto ela quanto ele querem coisas diversas e, porque não concordam e nem entram em pacto, tem início o estágio de medição de forças de que os poemas são, afinal, o campo de batalha. De fato, ele 
tentara seduzi-la com medidas próprias: com formas poéticas, com expedientes lingüísticos, com imperialismos literários, com lábia e até com erotismo. E quer nos passar a impressão de que luta contra si mesmo: afinal, o texto é de sua lavra, é seu espaço particular; os cadernos também, a caneta, a tinta, a cola, as folhas. De modo que, emancipar do seu território privativo a Dama, pode parecer ser, da parte dele, um grande ato de bravura!

Por outro lado, a situação da Dama é muito delicada e complexa, e ela se vê num impasse. Sim, porque permanecer ali, que é o que ela quer contra a vontade dele, pode significar perpetuar-se à mercê de seu senhor, eternizar-se sob a sua tutela, seu domínio. Saltar do caderno pode significar, ao contrário, a alforria total.

No entanto, a sábia Dama não se engana. Ela se dá conta de que o que está em questão não é um simples problema maniqueísta de sim e de não, e, muito menos, uma exclusão de contrários. $\mathrm{O}$ nó é outro. E daí que ela opte por algo muito mais significativo e louvável. De modo que ela se decide por uma terceira alternativa. Ou seja: ela se decide pelo direito de decidir, de escolher onde quer estar - expediente que até então lhe era estranho e ilegítimo. Reparem que tal diligência ultrapassa, em muito, o estado de passividade e de submissão em que se situava até agora.

Por esse viés, a prisão dentro da página passa a ser, ao contrário do que antes parecia, uma forma de libertação! Para a Dama da Cantiga d'Amor, a determinação de continuar a permanecer recolhida, em vez de se deixar emancipar pelo seu Cavaleiro, parece ser o único modo de, no contexto medieval que a rodeia, obter a sua autonomia.

E é assim que, nessa nova acepção de Ana Luísa Amaral, a cela feminina acaba se tornando sinônimo de liberdade. Porque, reparem, não é a Dama que salta do texto, mas é ela quem, por vontade e decisão próprias, expulsa do seu texto o Trovador:

Pronto, agora, sim,

que bem que aqui estou:

sapatinho raso

a verso feliz.

Já disse: não quero,

ide-vos daqui. (Amaral 2013: 52; meus sublinhados) 
Ufa! Ainda bem que trouxe para este desembocar a graça e o humor negro de Ana Luísa Amaral. Só assim o citado poema de Cecília Meireles não nos fica ecoando tão funéreo quanto nos pareceu no princípio da minha fala, quando o "sal" era, apenas e tão-somente, lágrimas, interditos de olhar, um ácido componente do "muro" das prisões em que se encarceram as mulheres.

\section{NOTAS}

\footnotetext{
${ }^{1}$ Mariana Ianelli vê, com propriedade, nessa obra de Horta, a cumplicidade entre Unicórnio e Dama como uma alternância de imagens: "Maria Teresa Horta abre sua longa série de poemas, alternando os papéis da dama e do unicórnio num jogo de espelhos" (Ianelli 2014: 34).

${ }^{2}$ Com razão, em sua resenha sobre este livro de Amaral, Mariana Ianelli reflete que "suas paisagens se fazem de entranhas, de possibilidades de ser, são paragens de reflexão em meio aos mares navegáveis da escrita" (Ianelli 2013).
} 


\section{Bibliografia}

Amaral, Ana Luísa (2013), Vozes (posfácio de Vinicius Dantas, orelhas de Yara Frateschi Vieira), São Paulo, Iluminuras.

Evola, Julius (1975), La Tradición Hermética, trad. Carlos Ayala, Barcelona, Martinez Roca. Horta, Maria Teresa (2013), A Dama e o Unicórnio (com CD contendo Cantata Profana de Antonio de Sousa Dias e poesia dita por Ana Brandão), Lisboa, Dom Quixote.

Ianelli, Mariana (2014), “O mundo da dama e do unicórnio”, Valor n. 687, Ano 14, 10, 11 e 12 de janeiro,São Paulo, 35-36.

-- (2013),"Reinvenção de mitologias”, Prosa, O Globo, 9 de novembro, Rio de Janeiro.

Meirelles, Cecília (1997), "Prisão", In António Carlos Secchin (org.), Miguel Sanches Neto (intr.), Eliane Zagury (biogr.), Ana Maria Domingues de Oliveira (fort. Crít.), Obra Completa, Rio de Janeiro, Nova Fronteira, 4 vols,1759-1760.

Maria Lúcia Dal Farra é pesquisadora do CNPq (onde até julho de 2016 integrou o Comitê Assessor deLetras do CNPq como um dos seus quatro membros), tendo sido professora de Literatura Portuguesa na USP, na UNICAMP, na UFS (onde foi Pró-Reitora de Pós-Graduação e Pesquisa) e em Berkeley (Universidade da Califórnia). Tem mais de uma centena de ensaios publicados sobre Literatura Portuguesa e Literatura Comparada, assim como obras sobre Vergílio Ferreira, Herberto Helder e Florbela Espanca. É também poetisa, tendo recebido o prêmio Jabuti de Poesia de 2012 por Alumbramentos. 